\title{
Amartya Sen'in Kapasite Yaklaşımı ve İnsan Merkezli Bir Kalkınma Anlayışı ${ }^{1}$
}

Mehmet Sedat ŬGUR, Department of Economics, Faculty of Economics and Administrative Sciences, Cukurova University,Turkey; e-mail: sugur@cu.edu.tr

\section{Amartya Sen's Capability Approach and A Human Centred Development View $^{2}$}

\begin{abstract}
Actual development can eventuate only in a society where the focus is enriching human lives. An approach, which focuses the expansion of income or economic outcomes, is inadequate to explain such a process; a high income by itself was no defense against human deprivation, because many human choices extend far beyond economic well-being. Amartya Sen's influential "capability approach" constitutes the philosophical and conceptual foundation of a human centered development view. There, human development approach stands as a considerable progress in development. This approach focuses on people's basic capabilities and their freedom by putting them in center of its analysis. Then, this study includes the investigation of the contents and development of this approach.

Keywords : Capability Approach, Human Development, Economic Development.

JEL Classification Codes : $\quad$ O10, O15, I31.

Öz

Gerçek anlamda bir kalkınma ancak, insanların yaşamlarını özgür bir biçimde sürdürebildikleri bir toplum içerisinde gerçekleşebilir. Yalnızca gelir artışının veya çıktı düzeyinin artırılmasını içeren iktisadi bir anlayış, böylesi bir süreci açıklamada yetersiz kalır. Gelir artışı, tek başına insani yoksunluğu açıklayamaz çünkü insanların tercihleri, iktisadi refahın çok ötesindedir. Amartya Sen'in "kapasite yaklaşımı", insan merkezli bir kalkınma anlayışının felsefi ve kavramsal altyapısını oluşturur. Merkezine insanı alarak, onun temel kapasitelerine ve özgürlüklerine odaklanan insani gelişme yaklaşımı da, bu bağlamda yeni bir kalkınma anlayışının önerilmesinde ve bu kalkınma sürecinde önemli bir yer tutar. Bu çalışma da bu anlayışın gelişimi ve içeriğinin incelenmesini içerir.
\end{abstract}

I Bu çalışma, Çukurova Üniversitesi, Sosyal Bilimler Enstitüsü, İktisat Anabilim dalında 2011 yılında tamamlanmış olan "İnsani Gelişme Yaklaşımı ve Neoliberal Politikaların Gelişmekte Olan Ülkeler Açısından Karşılaştırılması” başlıklı yayımlanmamış yüksek lisans tezinden yararlanılarak oluşturulmuştur.

2 This study has developed from unpublished master thesis titled as "Comparison of Human Development Approach and Neoliberal Policies for Developing Countries" which had completed in Cukurova University, Institute of Social Sciences, and Department of Economics in 2011. 


\section{Giriş}

Kalkınma, en geniş anlamda, insanların yaşamlarını özgür bir şekilde sürdürebildiği bir toplum içerisinde gerçekleşebilir. Dolayısıyla sadece ekonomik çıktının veya kişi başına gelirin artırılması gibi ekonomik göstergelerle ifade edilen bir 'kalkınma' anlayışı böylesi bir süreçte anlamsız kalır. O halde kalkınmanın asıl içeriğine ulaşabilmek için, sosyal, siyasal ve kültürel olmak üzere diğer birçok niteliksel değişkenin de göz önünde bulundurulması gerekir. İnsanların özgürlüklerinin ve kapasitelerinin genişletilmesi ve yaşam standartlarının yükseltilmesi süreci olarak görülmesini içeren Amartya Sen'in kapasite yaklaşımı da kalkınmada böyle bir anlayışı içerisinde barındırır. Kalkınmanın insanların kapasitelerinin genişletilmesi süreci olarak görülmesi, aynı zamanda geleneksel kalkınma anlayışına bir meydan okuma niteliğini de taşır. Böylece, insan refahının geleneksel anlayışın ifade ettiği gibi tek başına 'fayda' ile ölçülemeyeceği, asıl ele alınması gerekenin, insanın bazı temel şeyleri yapmaya muktedir olduğu 'temel kapasiteleri' (basic capabilities) olduğu ortaya konmuş olur. İşlevli hale getirilebilen bu kapasiteler, aynı zamanda bireysel özgürlüğün de önkoşuludur (Sen, 1979: 218; Sen, 1993: 33). İnsanların özgürlüklerinin genişletilmesini içeren kapasite yaklaşımı, insanları kalkınma sürecinin merkezine koymasıyla önem arz eder. Dolayısıyla aynı zamanda etik bir kalkınma anlayışının da temelleri atılmış olur.

Kalkınma anlayışında etik konusu gündeme geldiğinde, iktisadın özellikle marjinalist devrimle birlikte büründüğü bilimsel kıstaslarından uzaklaşıldığı kabul edilir. Çünkü iktisat kuramına göre, tüm bireyler akılcı bir biçimde kendi çıkarlarının peşinde koşarlar. Öyle ki Adam Smith, iktisadın temel taşı olan ünlü Ulusların Zenginliği adlı eserinde, insanları harekete geçiren olgunun ‘durumlarını iyileştirme arzusu' olduğunu vurgularken, bunun için de en kaba yöntemin 'servet artırımı' olduğuna değinir (Smith, 1994[1776]: 372). Dolayısıyla da, insanların çok çeşitli tutkularca sürüklendiğinin farkında olmasına rağmen, buradaki insan davranışında genelde akılcı bir yaklaşımı ön planda tutar. Böylece kişisel çıkarcı olarak nitelendirilen bireylerin davranışlarının görünmez bir elin marifetiyle toplumsal kazançta bir artışa yol açtığına ilişkin temelde rasyonel bir yaklaşım ortaya atılmış olur. İnsan eyleminin bir rasyonel seçime indirgenmesi ile karakterize edilmiş böylesi bir rasyonel birey de, sonuç olarak tahmin edilebilir bir birey haline gelir. Ancak A. Sen'e göre, kendi tercih davranışında hiçbir tutarsızlık göstermeyen böylesi tahmin edilebilir bir birey ancak dar anlamda rasyonel olabilir. İnsanların motivasyonları çoğul olduğundan kişisel çıkar dürtüsü tek başına insanlığı yönlendiremez. İnsanlar, temel olarak benzer değildirler. Gerçekte, sağlık, uzun ömürlülük, iklim koşulları, yaşanılan yer, iş koşulları, mizaç ve hatta vücut ölçüleri bakımından farklılıklar gösterirler. Dolayısıyla, gerçekleri görebilen bir etik anlayışı için, insanların tutkularını ve çıkarlarını daha geniş anlamda değerlendirmek gerekir (Sen, 1979: 215).

Bu bağlamda, Amartya Sen'in 1980'lerin başından itibaren üzerinde durduğu, insani gelişme yaklaşımının da temelini oluşturan ve hem felsefi hem de iktisadi olarak güçlü bağlara sahip olan kapasite yaklaşımı, bu çalışma için önem arz eder. Kapasite 
yaklaşımından ilham alan insani gelişme yaklaşımı ile birlikte kalkınmanın hedefi, eğitim, sağlık ve yaşam standardı olmak üzere üç temel kapasitenin genişletilmesi yoluyla insan yaşamının değerinin artırılması halini almıştır. Bu çerçevede Kalkınma İktisadı'nda yeni bir anlayış ortaya çıkaran kapasite yaklaşımı ve bu yaklaşımdan türetilen insani gelişme yaklaşımının temel unsurları bu çalışmanın öncelikli inceleme alanını oluşturmaktadır. Ardından, insani gelişme anlayışına göre Birleşmiş Milletler Gelişme Programı (UNDP) tarafından yayımlanan İnsani Gelişme Raporları'nda oluşturulan İnsani Gelişme Endeksi, yine bu çalışmanın içerisinde incelenecek diğer bir temel konudur. Geleneksel iktisadi anlayış, insan refahını ölçmek için fayda temelli olarak ve merkezine geliri alarak kişi başına GSMH'yi kullanır. Ancak bu ölçütün, insan yaşamını veya insanın değer verdiği unsurları ölçmede sorunlar yaşadığı bir gerçektir. Öyle ki, R.F. Kennedy de 1968'de Kansas Üniversitesi'ndeki konuşmasında, eğer insan yaşamı GSMH ile değerlendirilirse, Amerika'nın dünyadaki en yüksek GSMH değerine sahip olduğunu, ancak bu ölçümün hesaplanmasının içerisinde birçok eksiklik barındırdığını belirtir. Konuşmasını da "GSMH, hayatı değerli kılan unsurlar hariç, her şeyi ölçmektedir” şeklinde etkili bir cümleyle bitirir. Bu bağlamda, ölçüme hayatı değerli kılan gelir dışındaki unsurların eklenmesi ve kalkınma anlayışında analizin merkezine insanın konması oldukça önemlidir. Bu bağlamda, bu çalışmada en temel anlamda insan merkezli bir kalkınma anlayışının özellikleri, avantajları ve ayrıca konuya yönelik eleştiriler incelenecektir.

\section{Kalkınma İktisadı'nda İnsan Merkezli Bir Anlayışın Gelişimi}

Sanayi devrimiyle birlikte endüstriyel dönüşüm süreci yaşayan -çoğu zaman İngiltere olmak üzere- gelişmekte olan ekonomilerle ilgilendikleri için ilk dönem iktisatçılarının hepsi, bir açıdan aslında kalkınma iktisatçısı olarak ifade edilebilir (Bardhan, 1993: 130). Bu iktisatçılar tarafından kalkınma kavramı genellikle, ilerleme, sanayileşme, modernleşme, genişleme, büyüme gibi kavramlarla eşdeğer olarak kullanılmıştır. Ancak her ne kadar Adam Smith, David Ricardo, John S. Mill, Thomas Malthus gibi Klasik İktisat'1n öncü isimlerinin çalışmalarında kalkınmanın kavramsal olarak incelenmesi söz konusuysa da, bu kavram, bu ilk yıllarında bağımsız bir inceleme alanı olarak görülmemiş, iktisadın bütünü içerisinde incelenmiştir. II. Dünya Savaşı sonrasında, uluslararası sistemde bir yandan siyasi bağımsızlığına kavuşan yeni ülkelerin yönetimi acil bir sorun olarak ortaya çıkmış, diğer yandan da Batı ülkelerinin, yeniden yapılanmalarını sağlamak için barış ortamı yaratma hedefleri ön plana geçmiştir. Bu çerçevede "Kalkınma İktisadı" adlı yeni disiplin, daha önceki yıllarda üzerinde fazla durulmamış olan azgelişmiş veya gelişmekte olan ülkelerin iktisadi sorunlarını karşılamak üzere ortaya çıkmıştır.

Azgelişmiş veya gelişmekte olan ülkelerin koşullarını inceleyen iktisatçıların, bu ilk yıllarda, bu ülkeler için en önemli amacı belirli bir büyüme hedefi sağlamak olmuştur. $\mathrm{Bu}$ ilk yıllarda ele alınan temel konular ise, sanayileşme, hızlı sermaye birikimi, işsiz emeğin hareketliliği ve planlama ile iktisadi olarak aktif hükümet olmuştur. Öyle ki, bu yeni disiplinin kurucularından sayılan Rosenstein-Rodan (1943), azgelişmiş ülkelerde sanayileşmenin hem bu ülkelerin hem de tüm dünyanın çıkarına olduğunu; bu ülkelerin sanayileşme yoluyla yoksulluk kısırdöngülerinden kurtulabilmek için de büyük bir itişe ihtiyaç duyduklarını belirtmiştir. Benzer şekilde Nurkse (1961[1953]) de, "bir ülke yoksul 
olduğu için yoksuldur" şeklinde, azgelişmiş ülkelerin sürekli bir kısırdöngü içerisinde olduğunu belirtmiş ve bu ülkelerin, uluslararası kuruluşlar tarafından yapılacak yatırımlara ihtiyaç duyduğunu ifade etmiştir (Kaynak, 2007: 29). Yine Lewis (1954) de, kalkınmanın kâra-dayanmayan tarım sektöründe çalışan emek fazlasının kapitalist modern sektöre taşınmasıyla sağlanacağını öngören sınırsız emek arzı ile kalkınma modelini ortaya atmıştır. $\mathrm{Bu}$ bağlamda savaş sonrası ilk yıllarında disiplin içerisinde tüm ülkelerin bir Avrupa modelini takip etmeleri gerektiğini savunan modernizasyon teorileri (Rostow, 1960) ve yerli iktisadi büyümenin sağlanabilmesi için Güney ülkelerinin küresel ekonomiyle etkileşimini sınırlandırmalarını savunan yapısalcı teoriler ortaya çıkmaya başlamıştır (Singer, 1952). Disiplinin ilerleyen yıllarında ise, Güney ülkelerinin Kuzey ülkelerinin sömürüsü nedeniyle yoksul olduğunu savunan bağımlılık teorileri ön planda olmuştur (Frank, 1966). Burada, genel olarak disiplinin ilk yıllarında kalkınma iktisatçılarının kendilerine hedef olarak GSMH'da rakamsal bir büyüme gerçekleştirmeyi seçtikleri görülmektedir. Ancak 1950'lerin ve 1960'ların deneyimlerine bakıldığında; çoğu gelişmekte olan ülkenin iktisadi büyüme hedeflerine ulaşmalarına rağmen insanların yaşam düzeylerinin çoğu yönden aynı kalındığı görülmüştür, bu da kalkınmadaki bu kavramsal tanımlamada bir şeylerin yanlış olduğunun anlaşılmasına sebep olmuştur. Öyle ki, 1970'lerin ortasına gelindiğinde, çok yönlü ve baskın bir hedef olarak GSMH, elbette tamamen ve her yerde değil ama genel olarak tahtından indirilmiştir. Sonuçta kalkınmanın anlamı da, olması gerektiği gibi, eş zamanlı olarak büyüme ve yoksulluğun giderilmesi hedefleriyle ilgili bir süreç olarak değişmiştir (Thorbecke, 2009: 138).

Bu bağlamda 1976 yılında bir Uluslararası Çalışma Örgütü (ILO) konferansında, yoksulluğun giderilmesi için yoksulların beslenme, barınma, sağlık ve eğitim gibi temel gereksinmelerinin karşılanmasını hedefleyen temel ihtiyaçlar yaklaşımı (Streeten \& Burki, 1978; Streeten vd., 1981; Alkire, 2002a; Stewart, 2006) tartışılmış, ardından Dünya Bankası da bu konuyu gündemine almıştır (Stewart, 2006: 14). Bu yaklaşımın, i) yeterli gıda, barınak ve giyim gibi bir ailenin özel tüketimi için belirli asgari gereksinimleri ve ii) temiz içme suyu, kanalizasyon, sağlık ve eğitim olanakları gibi genellikle toplum tarafından ve toplum için sağlanan temel hizmetleri, içerdiği ifade edilmektedir (Thorbecke, 2009: 141). Ancak Sen, her ne kadar bu yaklaşımın, GSMH ve büyüme göstergeleri ile mücadelede olumlu bir rol oynadığına inansa da, onu derin temellere dayanan bir yaklaşım olarak görmenin bir hata olacağını belirtmiş ve diğer felsefi temelleri olan yaklaşımlardan destek alması gerektiğini savunmuştur (Sen, 1987: 25-26). Ancak, 1982 borç kriziyle birlikte gelişmekte olan ülkeler, daha yoğun olarak istikrar ve uyum politikalarına yöneldikleri için, bu yaklaşım da gereken bu desteği almaktan yoksun kalmıştır. Sonuç olarak da, meta-fetişizmine dayanması, özgürlüğe yetersiz önem vermesi, insanlar adına pasif bir durum içermesi ve felsefi yetersizliği gibi nedenlere dayandırılarak, temel ihtiyaçlar yaklaşımı, kapasite yaklaşımı daha fazla ön plana çıkıncaya kadar yoğun eleştirilere maruz kalmaktan kurtulamamıştır.

\section{Kapasite Yaklaşımı ve Kapasitelerin Genişletilmesi Olarak İnsani Gelişme}

1980’li yıllar kalkınma çalışmaları için krizlerin, ağır problemlerin ve gerilemelerin olduğu oldukça zor dönemleri ifade etmektedir. Yine de, bu dönemde şekillendirilen birçok çalışma, 1990'lı yılların başında ortaya atılan insani gelişme düşüncesinin kalkınmaya 
eklenmesine ve de sonraki yıllarda yoğun ilgi ile karşılanmasına neden olmuştur. İnsani gelişme anlayışının temel önemi, önceki yaklaşımların ya "emek arzı" ya da "sermaye" olarak gördükleri insanı, artık toplumun gerçek zenginliği olarak görmesinde yatar.

Kalkınma sürecinde insan refahının gerçek koşullarını anlamaya çalışırken, gelirin oldukça önemli bir etkiye sahip olduğu, ama yalnızca gelir çözümlemesiyle yetinilmemesi gerektiği düşüncesinin kabul edilmesi gerekir. Bununla ilgili olarak öncelikle Rawls (1971)'nn klasik 'birincil mallar' (primary goods) çözümlemesi önemlidir. Bu düşünce, insanların ayrı ayrı amaçlarından bağımsız olarak ihtiyaç duydukları kaynaklara ilişkin daha geniş bir görünüm sunar; bu anlayış, geliri ve aynı zamanda diğer genel amaçlı 'araçları' içerir. Birincil mallar, herhangi bir kişinin kendi amaçlarına ulaşmasına yardımcı olan genel amaçlı bir araçtır ve hakları, özgürlükleri ve fırsatları, gelir ve serveti ve özsaygının toplumsal temellerini içerir (Sen, 2004: 101). Ancak Sen (1979: 215)'e göre, Rawls'ın bu çözümlemesi de bazı problemleri içerisinde barındırır. Buna göre, Rawls'ın çözümlemesindeki gibi, eğer insanlar temel olarak oldukça benzerlerse, çıkarın değerlendirilmesi adına oluşturulacak bir birincil mallar endeksi oldukça yararlı olabilir. Ne var ki gerçekte insanlar, sağlık, uzun ömürlülük, iklim koşulları, yaşanılan yer, iş koşulları, mizaç ve hatta -yiyecek ve giyim ihtiyaçlarıyla ilgili olarak- vücut ölçüleri bakımından farklılıklar gösterirler. Dolayısıyla, çıkarı yalnızca birincil mallar açısından değerlendirmek, kısmen gerçekleri göremeyen bir ahlak anlayışına neden olur. Bu bağlamda, Amartya Sen, 1979'da, Rawlscı eşitlik ve faydacı yaklaşımın birleştirilmesi ile eşitlik üzerine yeni ve yeterli bir teorinin oluşturulup oluşturulamayacağını sorgular. Yeni bir yorum adına da daha önceki yaklaşımların eksik bıraktığı çerçevenin, bir insanın bazı temel şeyleri yapmaya muktedir olduğu 'temel kapasiteleri' olduğunu ortaya koyar (Sen, 1979: 218). Böylece Rawls'ın birincil mallar düşüncesindeki mallara odaklanma düşüncesinden -aynı zamanda mal fetişizminden de- uzaklaşılır. Çünkü malların karakteristiği bir kişinin bundan nasıl yararlanacağını göstermekten uzaktır. Dolayısıyla Sen'in düşüncesine göre artık kişinin işlevliliklerine (functionings) bakılması gerekir. Böylece de insanoğlunun bu mallardan nasıl yararlanacağı üzerine odaklanılmış olunur (Sen, 1999: 6).

Kapasite yaklaşımının Rawls'ın düşüncesi ile bağlantısı daha yeni olmakla birlikte, yaklaşımın çok eskiye dayanan bağlantıları da bulunmaktadır. Amartya Sen, kapasite yaklaşımını oluştururken, Adam Smith'in 'ihtiyaçlar' (necessities) ve yaşam koşulları üzerine analizinden ve Karl Marx'ın insanın özgürlüğüne ve serbest bırakılmasına ilişkin yaptığı vurgudan yararlanarak kavramın altyapısını oluşturmuştur (Clark, 2006: 32). Ancak yaklaşım, esas altyapısını ve kavramsal bağlantısını Aristo'nun siyasal bölüşüme ilişkin analizinde ortaya koyduğu eudaimonia (insan gelişimi/human flourishing) kavramında bulmuştur (Sen, 1993: 46).

Kapasite yaklaşımının en önemli özelliği olan, insanların kapasitelerine göre ne yapmaya ve ne olmaya muktedir olduklarına odaklanması düşüncesi, insanların arzu tatminine odaklanan felsefi yaklaşımlara veya gelir, harcama, tüketim, temel ihtiyaçların karşılanmasına odaklanan teorik ve pratik yaklaşımlara ters düşer. Kalkınma politikalarının tercihinde insanların kapasitelerine odaklanılması, derin bir teorik farklılaşma arz eder. $\mathrm{Bu}$ yönüyle de, neoliberal ve faydacı politika reçetelerine kıyasla oldukça farklı politikalar 
ortaya koyar (Robeyns, 2003a: 5). Yani insan refahı tek başına gelirle veya geleneksel olarak ifade edilirse fayda ile ölçülemez. Sorun insanın neye sahip olduğu değil, -kapasitesini gösteren- ne olduğu/olabileceği veya ne yaptığı/yapabileceğidir. Refah için önemli olan, fayda yaklaşımındaki gibi- tüketilen malların karakteristiği değildir. Sorun tüketicinin onu nasıl kullandığıdır. Örneğin, bir kitabın okuma-yazma bilmeyen biri için çok az değeri vardır. Öyleyse insan refahını ve yoksulluğu anlayabilmek için malları sahip olunabilirliklerinin ötesinde ve Sen'in işlevlilik (functioning) dediği, malların kullanımı açısından düşünmek gerekir. İşlevlilik malların verili karakteristikleriyle bir kişinin ne yapabileceğidir (Todaro \& Smith, 2009: 16). Bir kişinin kapasitesi de bu kişinin erişebileceği alternatif işlevliliklerin bir birleşimini yansıtır (Sen, 1993: 31). Kapasite yaklaşımı, işlevli hale getirilebilen kapasitelerin yaşam kalitesini değerlendirmesine yardımcı olmuş olur (Sen, 2005a, s. 4).

Sen (1999)'e göre, kapasite yaklaşımı, “kişinin farklı işlevlilik vektörlerine sahip olma ve buna ilişkin refah (well-being) erişimlerinden yararlanma kapasitesini”" refahın en iyi göstergesi olarak görür. İşlevlilik, "olma" ve "yapma" durumları gibi, bir kişinin kazanımlarını ifade ederken, metalar, bu işlevliliklere erişmek için kullanılır. Öyleyse;

$\mathrm{x}_{\mathrm{i}}$, i kişisi tarafından sahip olunan metaların vektörü, fonksiyon,

c (.), bir meta vektörünü, bu metaların karakteristiklerinin vektörüne çeviren

$f_{i}(),$.$i kişisinin bireysel "yararlanma fonksiyonu”,$

$F_{i}$, biri i kişisinin gerçekte seçebileceği olmak üzere, $f_{i}$ fonksiyonları seti,

Eğer kişi, $f_{i}($.$) yararlanma fonksiyonunu seçerse, x_{i}$ meta vektörüyle, erişilen işlevlilik fonksiyonu, $b_{i}$ vektörü ile;

$b_{i}=f_{i}\left(c\left(x_{i}\right)\right)$ olur.

Eğer kişinin meta tercihleri vektörü, $\mathrm{X}_{\mathrm{i}}$ seti ile kısıtlanırsa, o zaman kişinin en uygun işlevlilik vektörü $\mathrm{Q}_{\mathrm{i}}\left(\mathrm{X}_{\mathrm{i}}\right)$ seti ile tanımlanır:

$$
Q_{i}\left(X_{i}\right)=\left[b_{i} \mid b_{i}=f_{i}\left(c\left(x_{i}\right)\right) \forall f_{i}(.) \in F_{i} \text { ve } \forall x_{i} \in X_{i}\right]
$$

$\mathrm{Q}_{\mathrm{i}}\left(\mathrm{X}_{\mathrm{i}}\right)$ işlevlilik tercihleri altında, kişinin özgürlüğünü ve yetkilendirme olarak adlandırılan, $\mathrm{X}_{\mathrm{i}}$ metaları üzerindeki hâkimiyetini; $\mathrm{Q}_{\mathrm{i}}$ ise, $\mathrm{i}$ kişisinin kapasitelerini ifade eder. Kapasiteler, kişinin erişebileceği işlevliliğinin farklı bileşimlerini yansıtır (Sen, 1999: 7-9). Diğer bir ifadeyle, meta ve işlevlilik ayrımı üzerine, Sen (1999)'in çalışmasında verdiği bisiklet kullanma ile bisiklete sahip olma örneği ele alınırsa; bir bisiklet $\left(\mathrm{x}_{\mathrm{i}}\right)$, taşıt olarak düşünüldüğünde (c karakteristiği), kişi -kapasitesine bağlı olarak ( $\left.\mathrm{Q}_{\mathrm{i}}\right)$ - bisikleti, ya kullanabilecek ya da kullanamayacaktır. 
Daha da geniş olarak ifade edilirse, kapasite yaklaşımı, zevkler, mutluluk veya isteklerin tatminine dayanan kişisel fayda yaklaşımından; mal sepetlerine, reel gelire veya reel refaha odaklanan mutlak veya göreli zenginlik düşüncesinden; müdahalenin olmadığı kuralları içeren negatif özgürlük değerlendirmelerinden; birincil mallar düşüncesindeki gibi özgürlüğün araçlarının kıyaslanmasından, farklı bilgileri odağa koyduğu noktada ayrılır (Sen, 1993: 30). Bir kişinin kapasitesi, kişisel karakteristikler ve sosyal düzenlemeler de dahil olmak üzere bir çok faktöre bağlıdır. İnsan kapasiteleri, bireysel özgürlüğün önemli bir parçasını oluşturur (Sen, 1993: 33).

Qizilbash'a göre, Sen'in yaklaşımı, temel kapasiteler açısından, hayat kalitesi ve kalkınmanın değerlendirilmesi için diğer yaklaşımlara göre oldukça önemli bir yere sahiptir. İnsanların kapasiteleri, onların -sonuçlarda özgürlüğe dayanan- pozitif özgürlüklerinin derecesini ele alır. Kalkınma, kapasitelerin genişletilmesi süreci olarak görülmelidir ve bu bağlamda kalkınma, özgürlükte bir artıştır (Qizilbash, 1996: 146). Clark'a göre de Sen'in kapasite yaklaşımında üç nokta önemlidir: İlki, Sen herhangi bir liste oluşturmamıştır. Bunun yerine Sen, kapasitelerin seçimi ve ağırlıklandırılmasının bireysel değer yargılarına bağlı olduğunu vurgular. Dolayısıyla da hem pratik hem de stratejik açıdan 'nesnel olarak doğru' bir kapasiteler listesi oluşturmayı reddeder (Clark, 2006: 35). İkincisi Sen, bu yaklaşımın farklı alanlarda farklı değerlendirilmesini öngörür. Öyle ki, yoksulluk analizinin daha sınırlı kapasite setine ihtiyaç duyacağını belirtirken, insan refahı analizinin daha geniş bir çerçevede incelemeye tabi tutulması gerektiğini belirtir. Son olarak bu yaklaşım, tek başına yeterli bir değerlendirme ölçütü değildir. Tek başına bir adalet ve kalkınma teorisi oluşturmaz. Bireysel özgürlük, iktisadi büyüme ve etkinlik gibi kavramların da dikkate alınması ve yaklaşımın bu kavramlarla desteklenmesi gerekir (Clark, 2006: 35).

Kapasite yaklaşımı, sosyal tercih ve sosyal refah analizlerinin enformasyonel içeriğini genişleterek; sadece mutluluk veya açıklanmış tercihlerin ötesine geçip ahlaki ilkeleri de analize dâhil ederek çoğulcu bir anlayış kazanır. Bu bağlamda bu yaklaşım, işlevlilikler, özgürlük, çoğulculuk ve eksiklik olmak üzere dört esas kavramı içinde barındırır (Alkire, 2002a: 4-10). Alkire'ye göre, kapasite yaklaşımının içerik olarak tam bir yaklaşım olarak görülememesi, Sen (1992: 46-49)'in deyişiyle "tam olmama durumu", onun aslında önemli avantajlarından birini oluşturur, çünkü bu sayede tekrar tekrar dönülerek eksiklikleri giderilmeye çalışılabilir (Alkire, 2002a: 10).

Son otuz yıldır sayısız düşünür tarafından desteklenip genişletilmeye çalışılsa da, kapasite yaklaşımı bazı eleştirilere maruz kalmaktan da kurtulamamıştır. Öyle ki, Fleurbaey (2002: 73-74), kapasitelere odaklanmanın yetersiz olduğunu, 'sosyal oyunun' içeriğinde hangi firsatların tam olarak sunulacağının ve bu faktörlerin bireysel başarı veya başarısızlığı nasıl etkilediğinin bilinmek isteneceğini belirtir. Dolayısıyla da bu yaklaşımın etik birçok görüşü içerisinde barındırmasına rağmen bir belirsizlik taşıdığını ve farklı anlayış ve tartışmalara yol açtığını ifade eder. Diğer taraftan, kapasite yaklaşımı genelde, ne derece işlevsel (operational) olduğu konusunda (Sugden, 1993: 1953; Gasper, 2007: 357) ve çerçevesini tutarlı bir kapasiteler listesi ile desteklemediği için (Nussbaum, 2000) eleştiriye uğrar. Gasper (2002: 436) ise, insan yaşamının 'kalkınmanın, insan tercihlerinin genişletilmesi süreci’ olduğu şeklindeki bir görüşle ifade edilemeyecek kadar karmaşık 
olduğundan hareketle, yaklaşımın henüz gelişim aşamasında olduğunu, bir refah teorisi olarak yetersiz olduğunu ifade eder. Tercihlere yönelik aşırı vurgusunun, esas kavramlarının içeriğinin belirsiz olmasının ve iktisat ile felsefe arasındaki ilişkinin psikoloji, sosyoloji ve antropoloji gibi alanlara değinilmeden kurulmuş olmasının ise belirgin eksiklikleri olduğunu belirtir.

İnsani gelişme düşüncesi de, teorik altyapısını Sen'in kapasite yaklaşımında bulur. Ancak insani gelişmenin çok boyutluluğu, aynı zamanda onun boyutlarının ne olduğu sorgusuna da yol açar. Belirtildiği üzere Amartya Sen, kapasite yaklaşımını ortaya atarken, farklı boyutlar için düşünülmesi gereken herhangi bir liste sunmamıştır veya hangi kapasitelerin öncelikli olduğuna yönelik bir iddia ortaya koymaktan uzak durmuştur (Alkire, 2002b: 184). Ancak literatürde, temel kapasiteler listesi sunan bazı önemli çalışmalar da mevcuttur. Öyle ki, ilerleyen yıllarda yayımlanan İnsani Gelişme Raporları'nda sunulan İnsani Gelişme Endeksi, kapasiteleri üç temel boyuta indirgerken (UNDP, 1990; Anand \& Sen, 1994; Anand \& Sen, 1997), kapasite yaklaşımının gelişmesinde önemli bir yeri olan Nussbaum (2000) da merkezi insan kapasiteleri olarak on farklı boyuttan oluşan bir liste ortaya koymuştur. Benzer şekilde Robeyns (2003b) de, cinsiyet eşitsizliği ve kapasiteler üzerine yaptığı çalışmasında, yetki, ev işi ve piyasa dışı hizmet, boş zaman aktiviteleri, hareketlilik (mobilite), din gibi kapasiteleri içeren bir liste sunmuştur. Sen'in kapasitelerin genişletilmesi olarak kalkınma düşüncesi, insani gelişme yaklaşımının başlangıç noktasını oluşturur. Böylece kalkınmanın hedefi, sağlıklı olmak ve iyi beslenmek, bilgi sahibi olmak ve toplum yaşamına katılım sağlamak gibi bir kişinin olabileceği ve yapabileceği şeylerin sınırlarının genişletilmesiyle insan yaşamının değerinin artırılması halini alır (Fukuda-Parr, 2003: 303). Bu yaklaşımla birlikte aynı raporlarda hesaplanan İnsani Gelişme Endeksi de, insan kapasitelerinin üç temel boyutuna vurgu yapmaktadır. Bunlar, i) yaşamını sürdürmek ve sağlıklı olmak, ii) bilgi sahibi olmak ve iii) iyi bir yaşam standardına sahip olmaktır (UNDP, 1990: 12). Ancak, endeks oluşturulurken, neden bu üç kapasitenin (veya boyutun) tercih edildiği ve dolayısıyla neden bunların en önemli olduklarının anlaşılması önemlidir. $\mathrm{Bu}$ tercih yapılırken, evrensel olarak değeri olan ve eksikliği başka kapasitelerin eksikliğine neden olacak temel kapasitelerin seçilmesine özen gösterilmiştir. Böylece ortaya üç boyutlu bir endeks çıkmıştır. Ayrıca endeksin özellikle bölüşüm sorunlarından uzak durması ve ortalama erişimin bir ölçümü olması, endeks oluşturulurken verilen bir diğer önemli karardır (Fukuda-Parr, 2003: 305-306).

\section{4. İnsani Gelişme Kavramı ve İnsan Merkezli Bir Kalkınma Anlayışı}

II. Dünya Savaşı sonrası Kalkınma İktisadı adı altında kurulan yeni disipline karşı başlayan yoğun ilgi, öncelikle 1970'lerin petrol kriziyle, ardından 1982 borç kriziyle büyük darbe almıştır. Bununla birlikte, belirli büyüme rakamları yakalasalar bile, belirli bir süre sonra yeniden durgunluğa geçen ve de kalkınmalarını gerçekleştiremeyen ve hala yoksulluk içinde hayatını sürdüren insanların yaşadığı ülkelerin veri olduğu bir dünya sisteminde, başka bir kalkınma fikrine ihtiyaç duyulduğu, özellikle son otuz yılda fark edilmeye başlanmıştır. Böylece artık, bilginin gücüne dayanan yeni sosyal gelişim aşamasında insanı, kalkınmaya dâhil etmenin gereği anlaşılmıştır ve kalkınma daha çok, insan yaşamının kalitesinin adaletli olarak ve haklarının korunması ile tutarlı bir şekilde artırılması olarak 
düşünülmeye başlanmıştır. Sonuçta da, 1980'li yılların ortasında, başta Amartya Sen'in olmak üzere, bu konuda yapılmaya başlanan çalışmalar, sonucunu ilk olarak 1990 yılında Birleşmiş Milletler Gelişme Programı'nın Mahbub ul Haq öncülüğünde yayımlanan İnsani Gelişme Raporu'nda vermiştir. Bu rapor, daha sonraki y1llarda, düzenli olarak yayımlanmaya devam etmiştir. Bu çerçevede, kalkınmanın öncelikli amacının insanlara fayda sağlamak olduğu ve gelirin, insan yaşamının bütününü ifade etmediği öne sürülmüştür. Bu yeni yaklaşım, iktisadi büyüme, insan sermayesi formülasyonu, insan refahı veya temel insan gereksinimlerindeki geleneksel yaklaşımlardan farklılaştığını iddia eder. Bunu da geliri, insani gelişme için gerekli ama yetersiz bir girdi olarak görmesiyle sağlar. Burada insanlar, araçtan ziyade kalkınmanın sonucudur; kalkınma sürecinden pasif kazanç elde eden bireyler değil kalkınmanın aktif katılımcılarıdır (UNDP, 1990: 11). En temel anlamda, toplumlar asıl zenginliklerinin kendi insanları olduğunu fark etmedikçe, maddi refah takıntısı, insan yaşantısını zenginleştirme (veya insan refahını artırma) hedefini mutlaka örtbas edecektir (ul Haq, 1995: 15). Bu bağlamda bu yaklaşımla artık ulusların asıl zenginliği, kendi insanları olarak görülmüştür.

Buna göre, insanların daha uzun, sağlıklı ve eksiksiz yaşayabilmeleri için durumlarının düzeltilmesi, insani gelişme olarak tanımlanmıştır (Ranis \& Stewart, 2000: 49). Felsefesinin temelinde kapasite yaklaşımının yattığ insani gelişme yaklaşımı, özellikle son yıllarda, insan refahının ölçümünde iktisadi göstergelerin yanında diğer göstergelerin gerekliliğine yaptığı vurgu nedeniyle yoğun ilgiyle karşılanmıştır. İktisadi sürecin ölçümünü değil, insanların yaşadığı toplumda eğitim ve sağlık hizmetlerini içeren genel yaşam kalitesindeki zenginliğin sistematik sınamasının, insani gelişmenin ölçümü olarak sunulması, insan refahının ölçülmesine farklı bir bakış açısı kazandırmıştır (Sen, 2000: 18). $\mathrm{Bu}$ bağlamda ortaya yine aynı raporlarda sunulan İnsani Gelişme Endeksi atılmıştır. İnsani Gelişme Endeksi'nin ortaya çıkmasının nedeni, ulusal gelişmenin yalnız başına milli gelirle ölçülmesinin engellenmesi ve daha kapsamlı bir sosyo-ekonomik göstergenin yaratılması olarak görülebilir. Mahbub ul Haq'1n deyişiyle amaç, "milli gelir ölçümü gibi insan yaşamının sosyal etkenlerini görmezden gelmeyen bir ölçüm meydana getirmektir” (UNDP, 1999: 23). Ancak insani gelişme düşüncesi ölçülemeyen bazı kapasiteleri de içinde barındırdığından -aslında- herhangi bir ölçümün çok ötesindedir. Dolayısıyla İnsani Gelişme Endeksi (İGE) gibi endekslere çok fazla yoğunlaşmak -belki de- büyük hata olur. Bunlar her ne kadar -kabaca- yararlı göstergeler olsalar da insani gelişme düşüncesini tam olarak açıklayamazlar. Çünkü insani gelişme yaklaşımının asıl erdemi onun kalkınma evrimine getirdiği çoğulcu ihtimamdır, muhtelif istatistiklerin kavranmasına yardımcı olması için toplu bir ölçüm meydana getirmek değildir (Sen, 2000: 22). İGE özellikle, insani gelişmenin ölçülmesi için eksik bir ölçüm olarak görülebilir; endeks, yaşamdaki bir çok unsuru analizine dahil edememekte, yalnızca insan refahı için gereken üç temel unsuru içermektedir (Ranis vd., 2006: 324). Dolayısıyla da endeks, insan yaşamına yönelik böylesine karmaşık bir düşünceyi basitleştirmiş olur. Ayrıca, politik özgürlükler ve katılımcılık gibi referansları da hariç tutar. Başlangıcındaki bu iki temel eksikliğinden dolayı, hem insani gelişme endeksi, hem de daha genel çerçevede insani gelişme kavramı sürekli olarak eleştiriye maruz kalmaktadır (Fukuda-Parr, 2005: 117; UNDP, 2002: 53). Öyle ki, İGE, ortaya çıkışını takip eden yıllarda bazı iktisatçılar tarafından 'gereksiz' (McGillivray, 1991) veya ölçülen 
kalkınma unsurlarının daha önceden de yoğun olarak çalışılmış olmasına atfen 'tekerleğin yeniden icadı' (Srinivasan, 1994) olarak değerlendirilmiş, bazıları tarafından da 'dikkatle ele alınması gerektiği’ (Kelley, 1991) belirtilmiştir. Ancak ilerleyen yıllarda endeks, çoğu iktisatçı tarafından daha geniş bir kalkınma ölçümü olarak sahiplenilmiş ve geliştirilme uğraşı içerisine girilmiştir.

\section{5. İnsani Gelişme Endeksi’nin Avantajları ve Endekse Getirilen Eleştiriler}

İGE'nin en çok önem arz eden özelliği, kalkınma literatürüne insan refahının ölçülmesi konusunda ülke karşılaştırmaları yapılırken kişi başına düşen gelirin yanında sosyal göstergeleri de kapsayan bir ölçüm sunmuş olmasıdır. Böylece kalkınma, gelir ve servetin artırılmasından çok daha fazla bir şeyi ifade etmeye başlamıştır. Dolayısıyla bu endeks ile birlikte kalkınmanın yalnızca yüksek gelir anlamına gelmediği, bundan ziyade daha kapsamlı bir çerçevede ‘insani gelişmenin’ kastedildiği anlaşılmaya başlanmıştır. Ayrıca, düşük gelir düzeyine sahip bir ülkenin eğitim ve sağlık boyutlarında ilerleme kaydedebileceği ve insani gelişme gerçekleştirebileceği; bunun yanında örneğin, petrol zengini ülkelerinse kalkınma olmadan yalnızca büyüme gerçekleştirebileceği anlaşılmıştır (Todaro \& Smith, 2009: 51). Dolayısıyla İGE, literatürde insan refahının ölçümü konusunda çok boyutlu bir görünüm ortaya koymuş olmaktadır.

İGE, insanların tercihlerinin genişletilmesi adına insani gelişmede temel kapasitelerin ölçülmesi için ortaya çıkmıştır (ul Haq, 1995: 47). Buradaki 'insani' amaç önemli olmakla birlikte, araç-amaç ayrımının dikkate alınması adına da büyük önem taşır. Böylece politika yapıcılar, yalnızca araçlara odaklanmaktan uzaklaşıp, kalkınmanın esas amacına (sonucuna) odaklanmış olur (ul Haq, 1995: 50). İGE, ulusal öncelikleri göstermesi nedeniyle de önemlidir. Endeks değerlerine bakılarak, hangi ülkenin sosyal kalkınmayla birlikte iktisadi bir ilerleme gösterdiğini, hangilerininse bunu yapmaktan uzak olduğu anlaşılabilir. Böylece politika-yapıcılara performanslarını artırmaları için baskı sağlamış olur. Eğer bir ülke, insani gelişmesini sağlayabilirse, bu aynı zamanda potansiyel büyümesinin de göstergesidir. Eğitimli ve sağlıklı bir nüfus ile birlikte, doğru makroekonomik politikalar uygulanarak hızlı büyüme sağlanabilir. Ancak eğitimsiz ve sağlıksız bir nüfusa sahip olmak, sürdürülebilir bir büyümenin sağlanabilmesi için oldukça fazla bir zamana ihtiyaç duyulacağı anlamına gelir. Aynı zamanda İGE zaman içerisinde değişebilir bir özelliğe sahiptir (ul Haq, 1995: 54-56). Öyle ki, ortaya çıkışından bu yana da birçok defa değişkenlerinde ve hesaplanmasında değişikliklere uğramıştır. Ancak, değişen koşullar, bu değişimi de zorunlu kılmaktadır. Aslında İGE'yi oluşturan unsurların zaman içerisinde, ilave veriler kullanılabilir hale geldikçe ve yaşamın bazı temel unsurları evrensel olarak anlaşılıp ortadan kaldırıldıkça, değişmesi de beklenmelidir. Örneğin, yetişkinlerin okuma yazma bilmeyişi evrensel anlamda ortadan kaldırıldığında doğal olarak bu göstergenin artık kullanılmasına gerek kalmayacaktır (Fosu \& Mwabu, 2010: 3). Son olarak, İGE, ülkeler için bir erken uyarı sistemi niteliği de taşır. Öyle ki, hâlihazırda bazı ülkeler ayrıntılı insani gelişme endeksleri hazırlamaya başlamışlardır (ul Haq, 1995: 55).

İGE, ortaya çıkışını takip eden yıllarda, gelişmiş ülkeler için yapılacak hiçbir şey olmaması nedeniyle eleştirilmiştir. Buna göre, gelişmiş ülkelerin hepsi zaten yüksek 
okuryazarlık, yüksek doğumda yaşam beklentisi ve yüksek gelir düzeyi rakamları gösterdiğinden neredeyse maksimum düzeyde bir insani gelişme sağlamıştır (Kelley, 1991: 318). Dolayısıyla gelişmiş ülkelerin bu eylemsel anlamından uzaklaştırılıp analize dâhil edilebilmesi amacıyla, ilerleyen yıllarda asıl değişkenlerde değişikliklere gidilmiş, okula kayıt oranları değişken olarak kullanılmış veya 2010 yılı raporunda olduğu gibi beklenen eğitim yılı gibi farklı göstergeler kullanılmıştır (UNDP, 2010).

Endeks, değişkenlerin birleştirilmesi, değişkenlere verilen ağırlıklar ve değişkenler arasındaki korelasyon ilişkisi olması gibi nedenlerle yoğun eleştirilere uğramıştır (Kovacevic, 2010). Öncelikle üç farklı göstergenin ortalama erişimi gösteren bir toplam endeksinde bir araya getirilmesi (aggregation) eleştirilmiştir (Booysen, 2002: 141). Böylesi bir toplulaştırma, birbirlerinden farklı unsurların tek tek ele alınıp, bunları anlamlı bir endeks oluşturma çabası altında bir bütün haline getirme çabasına benzetilmiştir. Buna göre, iyi bir yaşam, refah ve eğitim firsatları, bir çıktı olan yaşam beklentisine; refah ve eşitlik gibi dışsal nitelikler eğitim gibi içsel bir niteliğe eklenmektedir (Veenhoven, 2007: 227). Gelir değişkeninin sağlık veya eğitim artışı meydana getireceği düşüncesinden hareketle, endeksteki üç değişkene verilen eşit oranda ağırlık da eleştiriye uğramıştır (Kelley, 1991; McGillivray, 1991). Todaro ve Smith (2009: 52) de bunun altında belirlenmesi zor olan bir değer yargısının bulunduğunu ifade etmişlerdir. Ancak, gelir ve gelir-dışı unsurların farklılığına vurgu yapan rapor (UNDP, 1993: 110), değişkenler arasındaki simetri ilişkisi ve nedensellik sıralamasının eksikliği nedeniyle üç değişkenden hangisinin daha ağır bastığının karar verilmesinin zor olduğunu belirtir. Bu nedenle, halen İGE'nin üç boyutu eşit ağırlıklı olarak kullanılıp endeks hesaplanmaktadır. Aynı zamanda buna bağlı olarak değişkenler arasında ve GSMH ile İGE arasında yüksek düzeyde korelasyon ilişkisinin bulunduğu iddia edilmiştir (Hopkins, 1991; McGillivray, 1991; Cahill, 2002: 887; Cahill, 2005: 1). McGillivray (1991)'in -özellikle- gelir ile yüksek korelasyona sahip olduğundan endeksi insani gelişme sürecinde gereksiz bir gösterge olarak görmesine karşılık, Ranis vd. (2006: 346, 349), korelasyonun aksak olduğunu ve böyle bir yargının özellikle de düşük gelirli ülkeler için geçerli olmadığını belirtmiştir. Dolayısıyla İGE'nin aslında kişi başına gelire göre daha kapsayıcı bir gösterge olduğunu, sosyal göstergelerle daha güçlü bir ilişki içerisinde bulunduğunu, bu nedenle de kişi başına gelire göre insani gelişmenin bazı temel unsurları için ülke performansları hakkında daha geniş kapsamlı bir ölçüm olduğunu ifade etmektedir. Öyle ki, kişi başına gelir tek başına kullanılırsa insani gelişmenin boyutlarını, İGE'den daha fazla eksik bırakmaktadır.

İGE'de kullanılan gelir dışındaki göstergelerin daha önceki yıllardaki çalışmalarda da kullanılmış olduğundan hareket eden ve kalkınma politikasına hiçbir yenilik getirmediğini savunan Srinivasan (1994: 241), endeksin kavramsal olarak zayıf, ampirik olarak geçersiz, belirli bir alan ve zaman boyunca da kıyaslanamaz olduğunu iddia etmiştir. Endeksteki verilerin zayıf, eksik, ölçüm hatalarına sahip ve yanlı olduğunu belirtmiştir. Buradan hareketle, farklı ülkelerin okuryazarlık tanımlarının bile farklı olduğunu, bu nedenle evrensel göstergeler kullanmanın hatalı olacağını ifade etmiştir. Buna göre, okula kayıt oranlarının; okulların kalitesi, terk oranları, okul süresi uzunluğu gibi ülke içi ve ülkeler arası değişkenlerin farklılığından dolayı uluslararası alanda kıyaslanabilir olmadığını belirtmiştir. 2009 yılı İGR'ye kadar bir eğitim göstergesi olarak kullanılan brüt okula kayıt 
oranı gerçekten de çoğu durumda eğitim durumunu olduğundan fazla gösterebilmektedir, çünkü çoğu ülkede ilkokula başlayan bir öğrenci okulu bırakıp bırakmadığı dikkate alınmaksızın okula kaydolmuş sayılır (Todaro \& Smith, 2009: 52). Aynı zamanda gerçekten de endeks hesaplanırken, bir kaç ülke için eğitim ve sağlık göstergeleri veri eksikliğinden dolayı belirtilen yıl için değil de çok daha önceki yılların verileri kullanılarak (UNDP, 2002: 152) hesaplanabilmiştir (Sumner, 2004: 14).

İGE'de gerçekten de kalitenin rolüne yönelik hiçbir endişe bulunmamaktadır. Örneğin sağlıklı bir yaşamı içeren fazladan yıllar ile yatağa bağımlı olma gibi sınırlı kapasiteleri içeren fazladan yıllar arasında büyük fark vardır. Dahası, 2010 y1lı İGE göstergelerinden biri olan eğitim yılı göstergesinde de yalnızca -sayı olarak- yılların dikkate alınmaması, bu eğitimin kalitesinin de hesaplanması gerekmektedir (Todaro \& Smith, 2009: 52). Ancak dikkat edilmesi gereken nokta, sağlık ve eğitim için yeni ve farklı başka göstergeler düşünülse bile dikkate alınacak yeni endeksin birçok ülke için yeterli veriye sahip olması gerekeceğidir (Todaro \& Smith, 2009: 52). Dolayısıyla bu da sosyal göstergelere ait verilerin elde edilmesinin zorluğunun anlaşılmasına yardımcı olabilir.

Endeksin, ortak eleştiriye uğradığı nokta şüphesiz yaşam kalitesini gösteren diğer sosyal erişimleri dışlamasıdır. Bu bağlamda endeksin siyasal özgürlük ve insan haklarını içeren farklı göstergelerle desteklenmesi gerektiği ve mevcut haliyle insani gelişmenin değerlendirilmesine yetersiz bir katkı yaptığı vurgulanmıştır (Kelley, 1991: 320, 323). Ancak, endekse siyasal göstergelerin eklenmemesi gerektiğini düşünen ve genel eğilimin de bu yönde olduğunu belirten Streeten (1994: 236), öncelikle özgürlüğün kendi içinde büyük bir önem arz ettiği ve belirli bir özgürlük kaybının diğer değişkenlerle desteklenemeyeceğini belirtir. Bununla birlikte, siyasal özgürlük değişkenlerinin İGE'deki diğer değişkenlere göre, ufak bir değişime karşı daha hassas olduğunu, daha düşük derecede nesnel olarak hesaplandığını, dolayısıyla endeksin toplam nesnelliğine zarar vereceğini ve bu yüzden de farklı endekslerle hesaplanmaları gerektiğini vurgular. Bu bağlamda, 2010 yılı IGR'de de, cinsiyet eşitliği, siyasal haklar ve çok boyutlu yoksulluk gibi unsurları analize dâhil eden farklı yeni endeksler hesaplanmıştır (UNDP, 2010).

Endeks, özellikle ülkelerin çevresel ve insani gelişme performansları arasındaki ilişki olmak üzere, kalkınmanın çevresel boyutunu da görmezden gelmektedir (Sagar \& Najam, 1998: 251). Ne var ki, ul Haq (1995: 58) yiyecek güvenliği, barınma, çevre gibi başka göstergelerin yeterli ve güvenilir verilere sahip oldukları zaman dikkate alınıp istenirse eklenilebileceğini ancak endekse daha fazla göstergenin eklenmesinin, endeksi geliştirmeyeceğini ve asıl göstergelere ve trende zarar vereceğini ifade etmektedir. Sen (2005b: x) de refah ve insani özgürlüğün siyasal, iktisadi, sosyal, yasal ve hastalıklarla ilgili birçok başka faktörden etkilendiğini ve İGE'nin ancak bu faktörlerin içinden birkaçının cesurca seçilmesiyle ve diğerlerinin dişlanmasıyla oluşturulduğunu ifade eder. Ancak, Sen (2005b: x)'e göre de, eklenen her yeni fazla değişken, bir diğerinin ve öncekilerin önemini azaltmaktadır. Bu nedenle daha fazla yeni göstergenin eklenmesi sorunu çözmeyecektir. Dolayısıyla Sen (2005b, s. xii), insani gelişme için gereken unsurların endeksteki eksikliğinden dolayı İGE ile genel olarak insani gelişme yaklaşımı arasında bir ayrıma gidilmesi gerektiğini ifade eder. 
Endeks aynı zamanda yoksulluk problemine uzak kalmakta ve Sen'in tanımlama ve birleştirme problemleri olarak ifade ettiği, kimin yoksul olduğu ve kaç kişinin yoksul olduğu gibi sorulara da cevap verememektedir (Sumner, 2004: 14). Alkire vd. (2015) de, İGE'nin ölçülmesindeki her değişken farklı kaynaklardan elde edildiği için, ölçümün bireylerin çoklu yoksunluklarını görmezden geldiğini ifade etmektedir. Son olarak endeks, ayrıca eşitsizlik problemini de dışlamaktadır. Eşitsizlik problemine göre, bir ülke diğerlerinden daha yüksek bir İGE değerine sahip olabilir ancak bu ülkede yoksulluk yaygın ve büyük gruplar kalkınma sürecinden dışlanmış olabilir (Foster vd., 2005: 25). Bununla ilgili olarak da 2010 yılı İGR'de eşitsizliği de analize dâhil eden bir Eşitsizliğe Uyarlanmış İnsani Gelişme Endeksi ve hanehalklarının çok boyutlu yoksulluğunu ifade eden bir Çok Boyutlu Yoksulluk Endeksi hesaplanmıştır (UNDP, 2010: 217).

\section{Sonuç ve Öneriler}

İnsanların sosyal ve ekonomik sürecin en önemli aktörü olması düşüncesi, aslında içinde herkesçe kabul edilen bir gerçekliği taşır. Bir ulusun gerçek zenginliği olan insanların, herhangi bir karşılık beklenmeden, temel kapasitelerinin genişletilmesi düşüncesi, gereksiz bir kalkınma anlayışını içerisinde barındırmaz. Aksine kalkınmada, önemli ve gerekli bir süreci ifade eder. Ancak kalkınma, uzun yıllar iktisadi olarak tanımlandığı ve genelde büyümeye odaklandığg için, ne yazık ki böylesi bir düşünceye gereken önem verilememiştir. Dolayısıyla, merkezine insanı koyan insani gelişme düşüncesinde temel kapasitelerin genişletilmesi ön plandadır. Bu yapılırken, ulusların esas zenginliğinin gelir artırımı değil, insanları olduğunun altı çizilmesi önemlidir. Herhangi bir toplumda, insanlarının yoksulluk ve sefalet içerisinde olmadığı, özgürce toplumsal aktivitelere katılım sağlayabildiği, bilgiye ve sağlık hizmetlerine ulaşabildiği, yani her anlamda belirli bir yaşam standardının üzerinde olduğu noktada insani gelişme sürecinden bahsedilebilir.

Amartya Sen'in kapasitelerin genişletilmesi olarak kalkınma düşüncesi, 1990 yılından sonra Mahbub ul Haq öncülüğünde düzenli olarak yayımlanmaya başlayan İnsani Gelişme Raporları'nda ortaya atılan insani gelişme yaklaşımının da temelini oluşturur. Böylece yalnızca gelir değil; bilgi, sağlık, temiz bir çevre, siyasal özgürlük ve hayatın basit zevkleri artık insani gelişmenin bir unsuru olmuş olur. Kalkınmanın hedefi, sağlıklı olmak ve iyi beslenmek, bilgi sahibi olmak ve toplum yaşamına katılım sağlamak gibi temel kapasitelerin genişletilmesi halini aldığı anda, insanın yaşamının değerinin artırılması ön plana geçmiş olur. Bu noktada gelire bağlı bir refah, arzu edilen bir unsur olmaktan çıkar, toplum, asıl refahın kendi insanları olduğunun farkına varır. Gelirin eleştirisini yapmak, elbette onu analizlerden dışlamak anlamına gelmez. Gelir, insan refahının yalnızca bir boyutudur. O halde, insanların gerçek yaşam düzeyleri hakkında fikir elde edebilmek için gelirin ve diğer faktörlerin bir arada dikkate alınması gerekir (Miller \& Wadsworth, 1967: 1197). Öyle ki, aslında yüksek gelirli ülkelerde en yüksek sağlık ve eğitim rakamlarının görülmesi şaşırtıcı değildir. Gelir, doğru kaynaklara aktarıldığ 1 zaman, gelirin kalkınma için elzem bir unsur olduğu sonucuna ulaşılmış olur. Bu bağlamda bilinçli bir kamu politikasının gelir artışını insanların yaşantılarına dönüştürmesi gerekir. Sonuçta da gelire dayalı büyümenin ötesine gidilmelidir. İnsanların yaşamlarının iyileştirilmesi olarak anlaşılan bir kalkınma anlayışıyla böylesi bir yaklaşımının merkezine konulan insanların, firsatlara eşit 
olarak erişimleri sağlanmalıdır. Bu çerçevede siyasal, sosyal ve kültürel faktörlere, iktisadi faktörler kadar önem verilmelidir. Fukuda-Parr (2003: 311-12) da bu bağlamda, insani gelişme sürecinin hızlandırılması için bir takım öneriler ortaya atmıştır. Bunlar, en temel anlamda eğitim ve sağlıkta iyileştirmeyi öngören bir sosyal kalkınma anlayışını, insani gelişmeye kaynak sağlayan bir iktisadi büyümeyi, insan haklarının korunması için siyasi ve sosyal, aynı zamanda da kurumsal reformları ve elbette tüm bireyler için insani gelişmenin temel unsurlarında adaleti içerir.

$\mathrm{Bu}$ çalışmayla birlikte, insani gelişme yaklaşımından türetilen İnsani Gelişme Endeksi'nin, insani gelişme sürecinin anlaşılması yolunda gerekli ama 'kaba' bir ölçüm olduğunun anlaşılması gerekir. Bu endeks, insani gelişmenin tam olarak anlaşılmasına yardımcı olamaz, çünkü siyasal özgürlükler, eşitsizlikler gibi birçok değişkeni ölçüme almakta sorun yaşar. Bu yüzden, bu ölçümün de ötesine gitmenin gerekliliğini savunan birçok çalışma (Ranis vd., 2006 gibi) söz konusudur. Bu nedenle aslında, İnsani Gelişme Endeksi ile genel olarak insani gelişme anlayışı arasında bir ayrıma gidilmesi gerekir. Öyle ki, insani gelişmenin değerinin anlaşılabilmesi için, yalnızca bu endekse odaklanmak hata olabilir. İnsani gelişme süreci, çok daha geniş anlamda bir kalkınma anlayışı sunar ve belirli bir kapasiteler listesine yönelik evrensel bir reçete belirtmez. İnsanların iyi ve yaşamaya değer bir hayat yaşayabilmesi için gereken özgürlükleri içerir. Tercihlerin ve kapasitelerin genişletildiği noktada önem arz eder. Bu bağlamda da, sürdürülebilir bir kalkınma anlayışı için eğitim ve sağlı başta olmak üzere, bireylerin kapasitelerinin geliştirilmesine önem verilmesi, yalnızca gelir artışına önem verilmesinden çok daha önemlidir. Eğer böylesi bir anlayışı ölçme çabası söz konusu ise, çok daha fazla kapasiteyi içeren bir ölçüm önerilebilir; ancak böylesi bir ölçümün de hangi göstergeye ne kadar ağırlık verileceği veya yeni eklenen göstergeler arasındaki korelasyon ilişkilerinin mevcut olup olmayacağı gibi sorunlarla karşı karşıya kalacağı da dikkate alınmalıdır.

\section{Kaynaklar}

Alkire, S. (2002a), Valuing Freedoms, New York: Oxford University Press.

Alkire, S. (2002b), "Dimensions of Human Development”, World Development, 30(2), 181-205.

Alkire, S. \& J. Foster \& S. Seth \& M.E. Santos \& J.M. Roche \& P. Ballon (2015), Multidimensional Poverty: Measurement and Analysis, Oxford: Oxford Univ. Press.

Anand, S. \& A. Sen (1994), "Human Development Index: Methodology and Measurement", Human Development Report Office Occasional Paper 12, New York: UNDP [Later published in S. Fukuda-Parr \& A.K.S. Kumar (eds.), Readings in Human Development (2nd ed.) (138151), New Delhi: O.U.P. 2005].

Anand, S. \& A. Sen (1997), “Concepts of Human Development and Poverty: A Multidimensional Perspective", Human Development Working Papers, New York: UNDP [Later published in S. Fukuda-Parr \& A.K.S. Kumar (eds.), Readings in Human Development (2nd ed.) (228-244), New Delhi: O.U.P. 2005].

Bardhan, P. (1993), "Economics of Development and The Development of Economics", The Journal Of Economic Perspectives, 7(2) Spring, 129-142.

Booysen, F. (2002), “An Overview and Evaluation of Composite Indices of Development”, Social Indicators Research, 59, 115-151. 
Cahill, M.B. (2002), "Diminishing returns to GDP and the Human Development Index”, Applied Economics Letters, 9, 885-887.

Cahill, M.B. (2005), “Is The Human Development Index Redundant?”, Eastern Economic Journal, 31(1) Winter, 1-5.

Clark, D.A. (2006), “Capability Approach”, in: D.A. Clark (ed.), The Elgar Companion to Development Studies, (32-45), Cheltenham: Edward Elgar Publishing Ltd.

Fleurbaey, M. (2002), “Development, Capabilities and Freedom”, Studies in Comparative International Development, 37(2) Summer, 71-77.

Foster, J. \& L.P. Lopez-Calva \& M. Szekely (2005), "Measuring the Distribution of Human Development: methodology and an application to Mexico", Journal of Human Development, 6(1) March, 5-29.

Fosu, A.K. \& G. Mwabu (2010), "Human Development in Africa", Human Development Research Paper 2010/08, June, N.Y.: UNDP.

Frank, A.G. (1966), “The Development of Underdevelopment”, Monthly Review, 18(4) September, 17-37.

Fukuda-Parr, S. (2003), “The Human Development Paradigm: Operationalizing Sen's Ideas on Capabilities", Feminist Economics, 9(2-3), 301-317.

Fukuda-Parr, S. (2005), "Rescuing The Human Development Concept From the HDI: Reflections on a New Agenda", in: S. Fukuda-Parr \& A.K.S. Kumar (eds.), Readings in Human Development (2nd ed.) (117-124), New Delhi: O.U.P.

Gasper, D. (2002), "Is Sen's Capability Approach an Adequate Basis for Considering Human Development?", Review of Political Economy, 14(4), 435-461.

Gasper, D. (2007), "What is the Capability Approach? Its Core, Rationale, Partners and Dangers", The Journal of Socio-Economics, No. 36, 335-359.

Hopkins, M. (1991), "Human Development Revisited: A New UNDP Report", World Development, 19(10), 1469-1473.

Kaynak, M. (2007), Kalkınma İktisadı (2. bas.), Ankara: Gazi Kitabevi.

Kelley, A.C. (1991), "The Human Development Index: 'Handle with Care", Population and Development Review, 17(2) June, 315-324.

Kovacevic, M. (2010), "Review of HDI Critiques and Potential Improvements", Human Development Research Paper 2010/33, New York: UNDP.

Lewis, W.A. (1954), "Economic Development with Unlimited Supplies of Labour", The Manchester School of Economic and Social Studies, 22(2), 139-191.

McGillivray, M. (1991), "The Human Development Index: Yet Another Redundant Composite Development Indicator?", World Development, 19(10), 1461-1468.

Miller, W.L. \& H.A. Wadsworth (1967), "Improving Measures of Economic Development", Journal of Farm Economics, 49(5), Dec., 1193-1197.

Nurkse, R. (1961[1953]), Problems of Capital Formation in Underdeveloped Countries, New York: Oxford University Press.

Nussbaum, M. (2000), Women and Human Development, Cambridge University Press.

Qizilbash, M. (1996), "Capabilities, well-being and human development: A survey", Journal of Development Studies, 33(2), December, 143-162. 
Ranis, G. \& F. Stewart (2000), "Strategies for Success in Human Development”, Journal of Human Development, 1(1), 49-69.

Ranis, G. \& F. Stewart \& E. Samman (2006), "Human Development: Beyond the Human Development Index", Journal of Human Development, 7(3), 323-358.

Rawls, J. (1971), A Theory of Justice, The Belknap Press of Harvard University Press.

Robeyns, I. (2003a), “The Capability Approach: An Interdisciplinary Introduction”, Training Course preceding the 3rd Int. Conf. on the Capability Approach, Pavia, Italy (Sept.), <http://www.hd-ca.org/pubs/323CAtraining20031209.pdf>, 21.08.2010.

Robeyns, I. (2003b), “Sen's Capability Approach and Gender Inequality: Selecting Relevant Capabilities", Feminist Economics, 9(2-3), 61-92.

Rosenstein-Rodan, P.N. (1943), "Problems of Industrialization of Eastern and SouthEastern Europe", The Economic Journal, 53(210/211), 202-211.

Rostow, W.W. (1960), The Stages of Economic Growth: A Non-Communist Manifesto, Cambridge University Press.

Sagar, A.D. \& A. Najam (1998), “The Human Development Index: A Critical Review”, Ecological Economics, 25, 249-264.

Sen, A. (1979), “Equality of What?", The Tanner Lecture on Human Values, Delivered at Stanford University, May 22; [Later published in S. McMurrin (ed.), Tanner Lectures on Human Values (pp. 197-220), Cambridge University Press. 1980].

Sen, A. (1987), “The Standard of Living” (Lecture I and Lecture II), in: G. Hawthorn (ed.), The Standard of Living (1-38), Cambridge: Cambridge University Press.

Sen, A. (1992), Inequality Reexamined, New York: Oxford University Press.

Sen, A. (1993), “Capability and Well-Being”, in: M.C. Nussbaum \& A. Sen (eds.), The Quality of Life (30-53), Oxford: Clarendon Press.

Sen, A. (1999), Commodities and Capabilities, New Delhi: Oxford University Press [First published in 1985, Amsterdam: Elsevier].

Sen, A. (2000), “A Decade of Human Development", Journal of Human Development, 1(1), 17-23.

Sen, A. (2004), Özgürlükle Kalkınma, (çev. Y. Alogan), İstanbul: Ayrıntı.

Sen, A. (2005a), "Development As Capability Expansion”, in: S. Fukuda-Parr \& A.K.S. Kumar (eds.), Readings in Human Development (2nd ed.) (3-16), New Delhi: Oxford University Press.

Sen, A. (2005b), "Foreword", in: S. Fukuda-Parr \& A.K.S. Kumar (eds.), Readings in Human Development (2nd ed.) (vii-xiii), New Delhi: Oxford University Press.

Singer, H.W. (1952), “The Mechanics of Economic Development”, Indian Economic Review, 1(2) August, 1-18.

Smith, A. (1994[1776]), An Inquiry into The Nature and Causes of The Wealth Of Nations, (ed. E. Cannan), New York: The Modern Library.

Srinivasan, T.N. (1994), "Human Development: A New Paradigm or Reinvention of the Wheel?", The American Economic Review, 84(2) May, 238-243.

Stewart, F. (2006), "Basic Needs Approach”, in: D.A. Clark (ed.), The Elgar Companion to Development Studies (14-18), Cheltenham: Edward Elgar Publishing Ltd. 
Streeten, P. (1994), "Human Development: Means and Ends", The American Economic Review, 84(2), Papers and Proceedings of the Hundred and Sixth Annual Meeting of the American Economic Association (May), 232-237.

Streeten, P. \& S.J. Burki (1978), "Basic Needs: Some Issues”, World Development, 6(3) March, 411421.

Streeten, P. \& S.J. Burki \& M. ul Haq \& N. Hicks \& F. Stewart (1981), First Things First: Meeting Basic Human Needs in The Developing Countries, Washington D.C., Oxford University Press.

Sugden, R. (1993), "Review: Welfare, Resources, and Capabilities: A Review of Inequality Reexamined by Amartya Sen", Journal of Economic Literature. 31(4) December, 19471962.

Sumner, A. (2004), "Economic Well-being and Non-economic Well-being: A Review of the Meaning and Measurement of Poverty", UNU-WIDER Research Paper No. 30.

Thorbecke (2009), "Kalkınma Doktrininin Evrimi, 1950-2005”, İçinde: F. Şenses (der.), Neoliberal Küreselleşme ve Kalkınma (123-175), İstanbul: İletişim Yayınları.

Todaro, M.P. \& S. Smith (2009), Economic Development (10th edt.), Addison-Wesley. ul Haq, M. (1995), Reflections on Human Development. N.Y.: Oxford University Press. UNDP (1990), Human Development Report 1990, New York: Oxford University Press. UNDP (1993), Human Development Report 1993, New York: Oxford University Press. UNDP (1999), Human Development Report 1999, New York: Oxford University Press. UNDP (2002), Human Development Report 2002, New York: Oxford University Press. UNDP (2010), Human Development Report 2010, New York: Palgrave Macmillan.

Veenhoven, R. (2007), “Subjective Measures of Well-being”, in: M. McGillivray (ed.), Human Wellbeing: Concept and Measurement (214-239), New York: Palgrave Macmillan. 
Uğur, M.S. (2017), “Amartya Sen'in Kapasite Yaklaşımı ve İnsan Merkezli Bir Kalkınma Anlayışı”, Sosyoekonomi, Vol. 25(31), 91-107. 